\section{The effects of septal lesions in the Mongolian gerbil (Meriones unguiculatus)}

\author{
GARY E. BROWN \\ University of Tennessee at Martin, Martin Tenn. 38237
}

Mongolian gerbils (Meriones unguiculatus) given septal lesions were deficient in a passive avoidance task (PAR). They perseverated in running to a drinking tube and could not inhibit a previously reinforced response. This loss of inhibition in a PAR task following septal lesions is apparently constant across the species investigated. Unlike rats, septal gerbils did not display the hyperemotionality following the lesions.

There are a number of behavioral changes following septal lesions. In the rat, septal lesions produce rage and viciousness (Fuiton \& Ingraham, 1929 ; Brady \& Nauta, 1953; King, 1958). Other organisms such as the cat (Moore, 1964), the golden hamster (Sodetz, Matalka, \& Bunnell, 1967), and the squirrel monkey (Buddington, King, \& Roberts, 1967) do not exhibit this increased emotional reactivity following septal lesions.

In palatability studies, the septal rat is finicky and inhibits his intake of aversive tasting substances such as quinine more than a normal rat (Beatty \& Schwartzbaum, 1967). In most other tasks, septal rats and cats make perseverative errors. Septal rats overrespond on a DRL (differential reinforcement of low rates of responding) schedule and a fixed-interval schedule (Ellen \& Powell, 1962a, b). In a discriminated barpressing task, septal rats are deficient in inhibiting their responses in nonreinforced conditions (Schwartzbaum, Kellicutt, Spieth, \& Thompson, 1964). Septal cats are below normal in reversing a simple position habit (Zucker \& McCleary, 1964). In a passive avoidance task (PAR), septal rats and cats are also deficient in inhibiting their responses (McCleary, 1961; Kaada, Rasmussen, \& Kveim, 1972; Brown, Harrell, \& Remley, 1971). On the basis of these findings, McCleary (1966) has suggested that septal lesions produce a loss of inhibition in nonreinforced and punished situations

In the present study, the effects of septal lesions on PAR behavior was investigated in an increasingly popular $S$ for behavioral investigations, the Mongolian gerbil.

\section{SUBJECTS}

The Ss were 18 Mongolian gerbils (Meriones unguiculatus), approximately 90 days old at the time of surgery.

\section{APPARATUS}

A runway (18 $\times 6 \times 9$ in.) was separated from a startbox $(7 \times 6 \times$ 9 in.) by a guillotine door. At the opposite end of the runway, there was a metal drinking tube. A Standard Electric timer was automatically started when the guillotine door was raised. A contact relay was connected to the drinking tube in order to record the latency of crossing from the startbox to the drinking tube. During PAR test trials, a 2-mA shock was aut omatically delivered to the drinking tube when the $S$ made contact. The

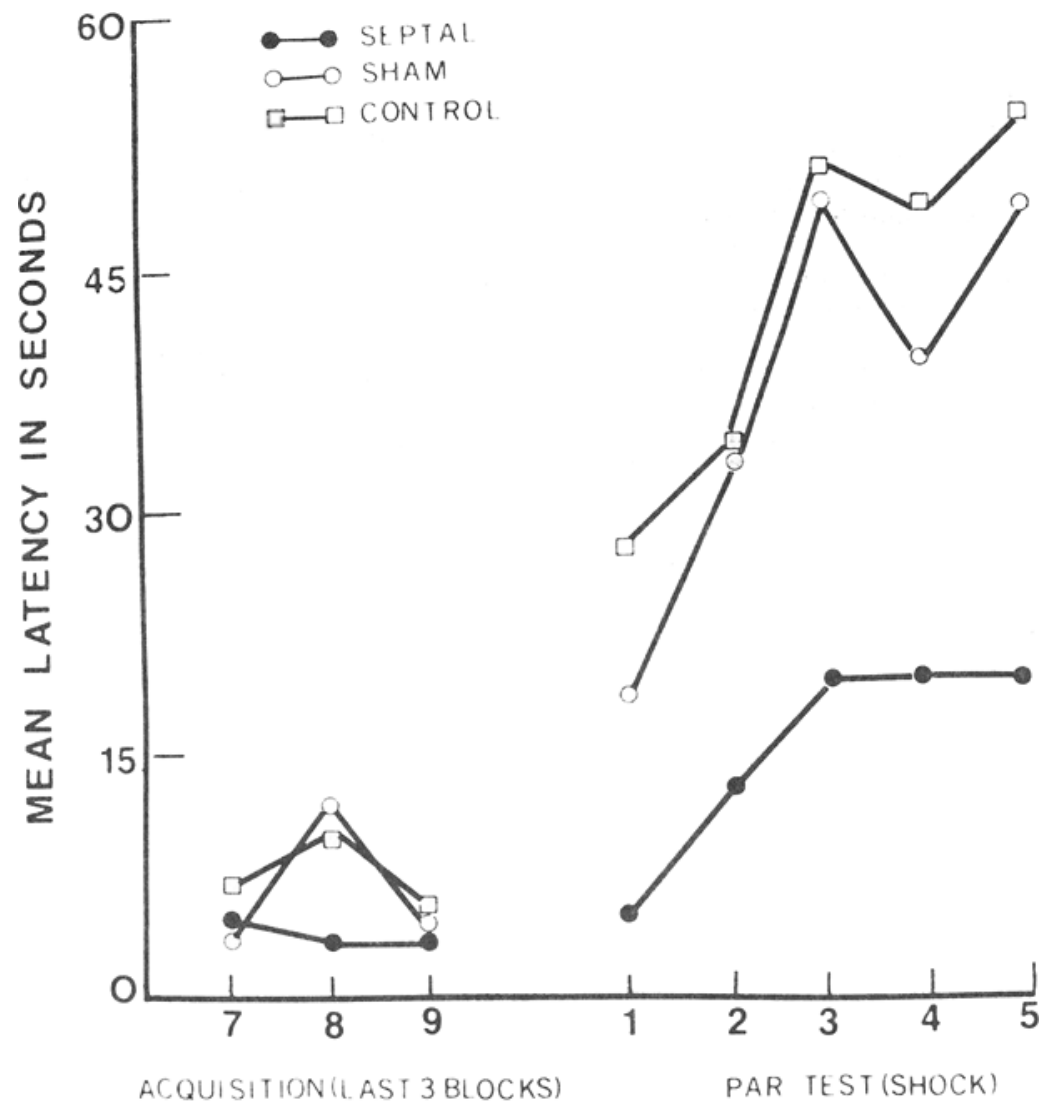

\section{BLOCKS OF FIVE TRIALS}

Fig. 1. Mean latency of crossing from the startbox to the drinking tube for lesioned and control Ss. 
sectioned at 40 microns. Every 10 th section through the area of the lesion was stained with thionine blue.

\section{PROCEDURE}

On Days 3.4 after the first day of surgery, all of the Ss were put on food deprivation and maintained at $85 \%$ body weight. The fifth day, each $\mathrm{S}$ was allowed to explore the apparatus with the guillotine door raised for approximately $10 \mathrm{~min}$. On Days 6-9, the Ss were given 10 trials per day in PAR acquisition. The Ss were put in the startbox, the door was raised, and the Ss were allowed to run down the runway to the drinking tube, which contained milk. The Ss were allowed to drink for 2-3 sec, and then they were placed back in the startbox. The intertrial interval was $10 \mathrm{sec}$. The $10 \mathrm{th}$ day, the $S s$ were given five trials following the procedure used on Days 6-9. On the last five trials of Day 10 , the drinking tube was electrified. After $60 \mathrm{sec}$, if the $\mathrm{S}$ did not drink, the trial was terminated and the $\mathrm{S}$ was returned to the startbox. The drinking cup was electrified for the entire 10 trials on Days 11-12.

$$
\text { RESULTS }
$$

Two lesioned Ss and one normal control $S$ were eliminated from the study because of sickness. An analysis of variance of the latencies on the last five acquisition trials revealed no reliable difference between the groups (Fig. 1). A Lesion by Trials analysis of variance of the latencies during which shock was present revealed a reliable difference between groups $(p<.01)$, a reliable trial effect $(p<.01)$, but no reliable interaction. A Newman-Keuls test showed that the septal animals had shorter latencies than either the sham group or the normal control group ( $F$ ig. 1 ).

Thote were no detectable differences in the septal lesions. The lesions extended from the posterior part of the medial parolfactorial area to an area just anterior to the fornix. The medial septal nucleus and the lateral septal nucleus were completely destroyed and the medial walls of the lateral ventricles were ruptured.

$$
\text { DISCUSSION }
$$

In the present study, gerbils with septal lesions were deficient in a PAR task. They perseverated in running to the drinking tube and could not inhibit a previously reinforced response. This is consistent with studies using other organisms. The septal cat (McCleary, 1961) and the septal rat (Brown et al, 1971) also perseverate in a PAR. Apparently, the loss of inhibition resulting from septal lesions is constant across the species tested.

The septal gerbils were different from septal rats in that they did not display the hyperemotionality that is seen in septal rats. A few of the septal gerbils were somewhat hyperreactive to handling, but they did not bite or display the viciousness that septal rats do. This "septal rage" appears to be specific to the rat. Gerbils with lesions of the ventromedial hypothalamus ( $\mathrm{VMH})$ do not display the viciousness that is seen in the VMH-lesioned rat. ${ }^{1}$

\section{REFERENCES}

BEATTY, W. W \& SCHWARTZBAUM J $S$. Enhanced reactivity to quinine and saccharine solutions following septal lesions in the rat. Psychonomic Science. $1967,8,483-484$.

BRADY, J. V. \& NAUTA, W. G H Subcortical mechanisms in emotional behavior: Affective changes following septal forebrain lesions in the albino rat. Journal of Comparative \& Physiological Psychology, 1953, 46, 339-346.

BROWN, G. E., HARRELL, E., \& REMLEY, N. $\ddot{R}$. Passive avoidance in septal and anosmic rats using quinine as the aversive stimulus. Physiology \& Behavior, 1971, 6. 543-546.

BUDDINGTON, R. W., KING, F. A., \& ROBERTS, L. Emotionality and conditioned avoidance responding in the squirrel monkey following septal lesions. Psychonomic Science, 1967.8, 195-196. ELLEN. P., \& POWELL, E. W. Temporal discrimination in rats with rhinencephalic lesions. Experimental Neurology, 1962a, $6,538-547$.

ELLEN, P., \& POWELL,E, W. Effects of septal lesions on behavior generated by positive reinforcement. Experimental Neurology, 1962b, 6, 1-11.

FULTON, J. F., \& INGRAHAM, F. D. Emotional disturbances following experimental lesions of the base of the brain. Journal of Physiology (London). $1929,67,27-28$.

KAADA, B. R., RASMUSSEN, E. W.. \& KVEIM, D. Impaired acquisition of passive avoidance behavior by subcallosal. septal, hypothalamic, and insular lesions in rats. Journal of Comparative \& Physiological Psychology, 1962, 55. 661-670.

KING F. A Effects of septal and amygdaloid lesions on emotional behavior and conditioned avoidance responses in the rat. Journal of Nervous \& Mental Disorders, 1958, 126, 57-63.

McCLEARY R A Response specificity in the behavioral effects of limbic system lesions in the cat. Journal of Comparative \& Physiological Psychology, 1961,54, 605-613.

McClEARY, R. A. Response-modulating functions of the limbic system: Initiation and suppression. In E. Stellar and J. M . Sprague (Eds.), Progress in physiological psychology. New York: Academic Press, 1966.

MOORE, R. Y. Effects of some rhinencephalic lesions on retention of conditioned avoidance behavior in cats. Journal of Comparative \& Physiological Psychology, 1964,57,65-71.

SCHWARTZBAUM, J. S., KELLICUTT, M. H. SPEITH, L. M.. \& THOMPSON, i. D. Effects of septal lesions in rats on response inhibition associated with food reinforced behavior. Journal of Comparative \& Physiological Psychology, $1964,58,217-224$.

SODETZ F. J MATALKA, E. S. \& BUNNELL, B. N. Septal ablation and affective behavior in the golden hamster. Psycnonomic Science, 1967, 7, 189-190.

THIESSEN, D. D., \& GOAR, S. Stereotaxic atlas of the hypothalamus of the Mongolian gerbil (Meriones unguiculatus). Journal of Comparative Neurology, 1971 , $140,123-128$.

ZUCKER, I. \& MCCLEARY, R. A. Perseveration in septal cats. Psychonomic Science, 1964, 1, 387-388.

\section{NOTE}

1. Brown, G. E., and Madks, H. The effects of VMH lesions in the Mongolian gerbil. In preparation. 